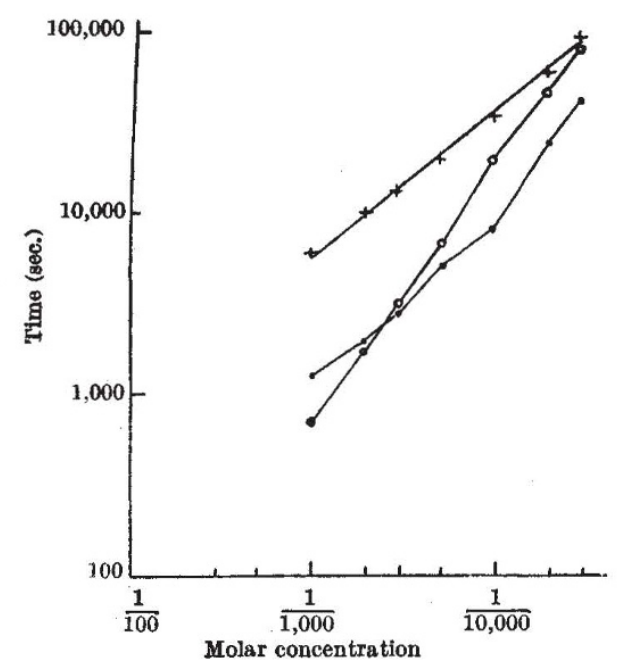

Fig. 2. - $\mathrm{x}-$, curve of death times; - - curve of decay beginning at anterior region; $-0-$, curve of decay beginning at posterior region. Toxlc agent: 4-methoxy-toluquinone

very striking manner. In higher concentrations of quinones, decay begins at the anterior region, in lower concentrations at the posterior region; so there is a certain concentration where an inversion of gradient occurs. An example is shown in Fig. 2. This indicates that at least two complexes of factors are involved in the histolytic process, the first being primarily effected by higher, the second by lower, concentrations.

Full details of the results obtained will be published elsewhere.

Zoological Institute,

$$
\text { L. v. Bertalaanffy }
$$

University of Vienna.

lst Chemical Laboratory,

O. HOFFMANN-OSTENHOF

O. SCHREIER

University of Vienna.

Oct. 11.

1 Hoffmann-Ostenhof, O., and Lee, W. H., Monatsh. Chem. (Vienna), 76, 180 (1946). Hoffmann-Ostenhof, Oo., and Biach, E., Monatsh.

2 v. Bertalanffy, L., Biologia Generalis (Vienna), 15, 295 (1942). Cf. also v. Bertalanffy, L., "Theoretische Biologie", 2 (Berlin, 1942).

' Cooper, E. A., Biochem. J., 7, 186 (1913). Cooper, E. A., and Nicholas, S. D., J. Soc. Chem. Ind., 46, T59 (1927). Oxford, A. E., and Raistrick, H., Chem. Ind., 61, 128 (1942). Oxford, A. E., Chem. Ind., 61, 189 (1942).

- Wallenfels, K., Chemie (Berlin), 58, 1 (1945).

${ }^{5}$ Herzog, R. O., and Betzel, R., Hoppe-Seylers Z. physiol. Chem. 74, 221 (19i1)., Cf. also Clark, A. J., "The Mode of Action of Drugs on Cells", (London, 1933).

- For example, Child, C. M., Protoplasma (Berlin), 5, 447 (1929).

\section{Action of Fluorine on the Teeth of Rachitic Rats}

Is previous communications, it has been shown that the action of fluorine on the dentin of the rat's incisor tooth depends on the Ca: $\mathrm{P}$ ratio of the diet ${ }^{1}$. With low $\mathrm{Ca}: \mathrm{P}$ ratio diets, fluorine causes a fine hypercalcified line in the predentin forming at the time of the injection, but on normal or high $\mathrm{Ca}: \mathrm{P}$ ratio diets, this does not happen, and the effects of fluorine on the predentin are not seen until it starts to calcify. It was suggested that this difference was due to the differences in the blood calcium level, as this is low with low $\mathrm{Ca}: \mathrm{P}$ ratio diets and normal or high with the other diets. This supposition has been tested in two ways : by raising the blood calcium of animals on the low $\mathrm{Ca}: \mathrm{P}$ ratio diet, and by lowering the blood calcium of animals on the high $\mathbf{C a}: \mathbf{P}$ ratio diet, and observing the effects of fluorine after this has been done.

Four litters of young rats were placed on a diet of low Ca: P ratio $(0 \cdot 25: 1)$, similar to that previously used, for 28 days. Three different procedures were then adopted: some were dosed with 27 r.U. of vitamin $\mathrm{D}$ by mouth and given an injection of sodium fluoride solution two days later; some were given only an injection of sodium fluoride solution, and some were only dosed with vitamin $D$. The rats were killed at intervals up to eight days after the sodium fluoride injection. Whereas the incisors of the rats given sodium fluoride alone all had the usual line in the predentin, the teeth of those previously given vitamin $\mathrm{D}$ showed either nothing at all or else an extremely faint line in the most proximal predentin. One litter was given a rather larger dosa of sodium fluoride than usual; all the rats getting sodium fluoride alone died in tetany, but those given vitamin $D$ before injection had no tetany and survived. It has been shown ${ }^{2}$ that vitamin $D$ dosage in rats on this diet causes a transient rise in blood calcium lasting 4-6 days.

Young rats from three litters were placed on the Steenbock and Black rachitogenic diet $(\mathrm{Ca}: \mathrm{P}$ ratio, $4: 1)$ for 28 days, and were then starved for $1,1 \frac{1}{3}$, $1 \frac{3}{4}, 2$ or 3 days. At the end of this time some were killed as controls and the rest given injections of sodium fluoride and returned to the diet. Many of the rats had violent tetany after the period of starva. tion, accentuated by the injection of fluoride, and two died. The rest were killed at intervals and examined. The four rats starved for one day showed no changes in their teeth due to the injection of fluoride. Of the other injected rats, two starved for $1 \frac{1}{3}$ days, and all the other rats, fifteen altogether, had the same hypercalcified line in the predentin as had previously been found in rats on the low Ca: P ratio diet given an injection of fluoride. Measurements showed that the line was laid down at the time of injection, and that the average incremental rate of predentin formation after that was $6 u$ per day. As is well known ${ }^{3}$, starvation causes a fall in the blood calcium of rats on high $\mathrm{Ca}: \mathrm{P}$ ratio diets, often to tetanic levels.

Thus under conditions when the blood calcium is raised, the action of fluorine on the predentin is greatly lessened or prevented, while when the blood calcium is lowered, this effect of fluorine is caused in rats previously found not to show it. These observations strengthen the theory previously put forward that the action of fluorine on the teeth is related to the level of the blood calcium.

The expenses of this work were defrayed by grants from the Council for Scientific and Industrial Research, and from the Staff Research Fund, Univer. sity of Cape Town.

Department of Physiology,

J. T. IRving

Medical School,

University of Cape Town.

$$
\text { Nov. } 9 .
$$

${ }^{1}$ Irving, J. T., Nature, 151, 363 (1943) ; J. Dent. Res., 22, 447 (1943). 2 Irving, J. T., J. Physiol., 155, 16 (1946).

${ }^{3}$ Cavins, A. W., J. Biol. Chem., 59, 237 (1924). Wilder, T. S., J. Biol. Chem., 81, 65 (1929). Kramer, B., Shear, M. J., and Siegel, J., J. Biol. Chem., 91, 271 (1931). 